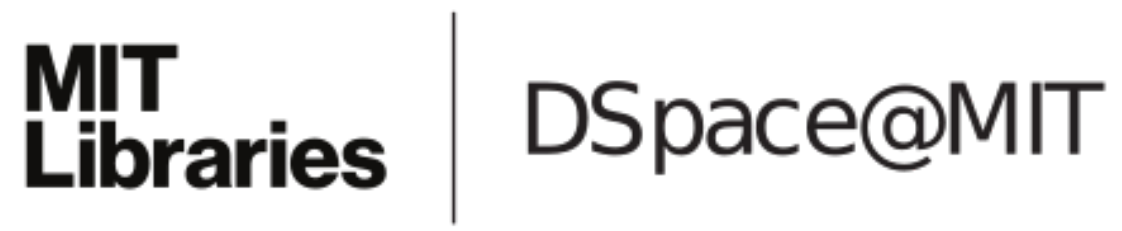

\author{
MIT Open Access Articles
}

Far-IR reflectance spectra analysis of $\mathrm{CdZnTe}$ and related materials

The MIT Faculty has made this article openly available. Please share how this access benefits you. Your story matters.

Citation: Yang, Tzuen-Rong et al. "Far-IR reflectance spectra analysis of CdZnTe and related materials." Hard X-Ray, Gamma-Ray, and Neutron Detector Physics XI. Ed. Ralph B. James, Larry A. Franks, \& Arnold Burger. San Diego, CA, USA: SPIE, 2009. 74490L-9. () 2009 SPIE--The International Society for Optical Engineering

As Published: http://dx.doi.org/10.1117/12.825874

Publisher: The International Society for Optical Engineering

Persistent URL: http://hdl.handle.net/1721.1/52741

Version: Final published version: final published article, as it appeared in a journal, conference proceedings, or other formally published context

Terms of Use: Article is made available in accordance with the publisher's policy and may be subject to US copyright law. Please refer to the publisher's site for terms of use. 


\title{
Far-IR reflectance spectra analysis of CdZnTe and related materials
}

\author{
Tzuen-Rong Yang ${ }^{1, *}$, Sheng-Hong Jhang ${ }^{1}$, Yen-Hao Shih ${ }^{1}$, Fu-Chung Hou ${ }^{2}$, Yu-Chang Yang ${ }^{2}$, \\ P. Becla ${ }^{3}$, Der-Chi Tien ${ }^{4}$ and Zhe Chuan Feng, \\ ${ }^{1}$ Department of Physics, National Taiwan Normal University, Taipei, Taiwan 116, ROC \\ ${ }^{2}$ Graduate Institute of Photonics \& Optoelectronics, National Taiwan University, Taipei, Taiwan \\ 106-17, ROC \\ ${ }^{3}$ Francis Bitter National Magnet Laboratory, Massachusetts Institute of Technology, Cambridge, \\ Massachusetts 02139 \\ ${ }^{4}$ Graduate Institute of Mechanical and Electrical Engineering, National Taipei University of Technology, \\ Taipei 10608, Taiwan, ROC \\ "corresponding author, Tel: 886-2-29346620-169, Fax: 886-2-22181221,e-mail: yang1@ntnu.edu.tw \\ \# e-mail:fengzc@cc.ee.ntu.edu.tw
}

\begin{abstract}
Far-infrared (FIR) reflectance spectroscopy has been employed to study the optical properties for a series of bulk $\mathrm{CdZn}_{\mathrm{x}} \mathrm{Te}_{1-\mathrm{x}}$ and $\mathrm{CdSe}_{\mathrm{x}} \mathrm{Te}_{1-\mathrm{x}}$ wafers. The zone-centre optical phonons for the ternary alloys show a variety of behavior patterns: they exhibit a "one-mode", "two-mode" or "intermediate-mode" behavior depending on the vibration characteristics of the end binary members. The CdSeTe called CST were found to be single-crystal with the zincblende structure. These four samples labeled with CST5, CST15, CST25, and CST35, which correspond with the composition of Se, $5 \%, 15 \%, 25 \%, 35 \%$, respectively. The intensity of CdTe-like TO band decays with $\mathrm{x}$ increasing, and the peak position increases from $140 \mathrm{~cm}^{-1}$ to $145 \mathrm{~cm}^{-1}$. In the other hand, the intensity of CdSe-like TO band grows with $\mathrm{x}$ increasing, and the peak position of CdSe-like TO band increases from $174 \mathrm{~cm}^{-1}$ to $181 \mathrm{~cm}^{-1}$. We use the model of dielectric function and using Least-Square fit to find the optical and transport parameters. By the infrared spectra analysis, we found the conductivity of $\mathrm{CdZn}_{\mathrm{x}} \mathrm{Te}_{1-\mathrm{x}}$ increase with increasing of $x$ value and the conductivity of $\mathrm{CdSe}_{\mathrm{x}} \mathrm{Te}_{1-\mathrm{x}}$ decrease with increasing of $\mathrm{x}$ value.
\end{abstract}

\section{Introduction}

Cadmium telluride, cadmium selenide and their seudobinary compounds are very suitable for various optoelectronic devices, such as photoconductors, photovoltaic detectors, photo-electro chemical and solar energy cells, and as substrates for growth of quantum wells and epitaxial layers of $\mathrm{HgCdTe}, \mathrm{HgZnTe}$ and HgMnTe [1, 2]. The II-VI-VI ternary semiconductor $\mathrm{CdSe}_{x} \mathrm{Te}_{1-x}$ possesses the zincblende structure for $x<0.36$. Its energy band gap $E_{\mathrm{g}}$ decreases as $x$ increases in this range. Beyond $x=0.4$, it exhibits the hexagonal structure with its energy band gap in- creasing until it reaches the value for pure CdSe [3]. Several studies of absorption [4] and reflec- tance [3, 5] reveal that $\mathrm{E}_{\mathrm{g}}$ versus $\mathrm{Se}$ composition $\mathrm{x}$ displays a large bowing effect, with the minimum value of $\mathrm{E}_{\mathrm{g}}$ occurring for $x$ between 0.36 and 0.5 .

There is considerable variation among data from different authors. Nahory et al. [6] have recently given expressions for the band gaps of the quaternary $\mathrm{ZnCdSeTe}$ and its boundary ternary alloys, including $\mathrm{CdSe}_{x} \mathrm{Te}_{1-x}$, as functions of composition at 4 and $300 \mathrm{~K}$. These results

Hard X-Ray, Gamma-Ray, and Neutron Detector Physics XI, edited by Ralph B. James, Larry A. Franks, Arnold Burger, Proc. of SPIE Vol. 7449, 74490L · (C) 2009 SPIE · CCC code: 0277-786X/09/\$18 · doi: 10.1117/12.825874 
motivate further study of the band gap. Earlier investigations of infrared (IR) reflectance [7,8] and Raman scattering [9] from $\mathrm{CdSe}_{x} \mathrm{Te}_{1-x}$ have shown the typical two-mode behavior of the long wavelength optical phonons. However, Perkowitz et al. [10] has reported a third mode which was attributed to substantial non-random clustering of the anions around the cations.

We present infrared and theoretical study of five zincblende $\mathrm{CdSe}_{x} \mathrm{Te}_{1-x}$ crystals with $x=0$ (i.e. pure CdTe), $0.05,0.15,0.25$ and 0.35 , and confirm that the previously observed third mode seen in infrared spectra is a bulk effect. Using a new type of optical spectrometer, we have successfully obtained room temperature spectra of these alloys, which were not detectable previously using an old type of scanning spectrometer. These data are compared to empirical and to first principles pseudopotential calculations.

The tunable lattice and band properties of $\mathrm{Cd}_{1-x} \mathrm{Zn}_{x}$ Te make it a useful Substrate material with potential for devices, and it is an interesting II-VI compound in its own right; yet there has not been much recent optical examination of its un- usual phonon modes. In the 1970s, three group-used infrared or Raman spectroscopy to study the transverse-optical (TO) and longitudinal-optical (LO) phonon modes in bulk $\mathrm{Cd}_{1-x} \mathrm{Zn}_{x}$ Te at $300 \mathrm{~K}$ and $80 \mathrm{~K}$. All three papers report two-mode be- havior, with similar plots of the CdTe-like and ZnTe-like TO and LO frequencies versus $x$ $[11,12,13]$. All show the remarkable result stated by Vodop'yanov et al. [12]; unlike every other two- mode system studied at the time, where one mode's TO frequency increases with $x$ and the other decreases, in $\mathrm{Cd}_{1-x} \mathrm{Zn}_{x}$ Te both frequencies grow with $x$.

\section{Experiment}

The samples were prepared by the Bridgman technique at Massachusetts Institute of Technology. $\mathrm{CdSe}_{x} \mathrm{Te}_{1-x}$ alloys were prepared by reacting the $99.9999 \%$ pure elemental constituents at $\sim 1150^{\circ} \mathrm{C}$ in evacuated, sealed quartz tubes. These were regrown by directional solidification at rates of 0.8-1 mm/h in a Bridgman- Stock- barger-type furnace. The resultant boules were cut into slices, 1-2 mm thick, and perpendicular to the growth axis. These were annealed at $650^{\circ} \mathrm{C}$ in a Se atmosphere, to improve the crystalline perfection. Consequently they were lapped, polished, and etched in a bromine-methanol solution. The alloy compositions were set by the ratio of constituents before growth, and confirmed by X-ray diffraction and transmission measurements after preparation. These samples were found to be single-crystal with the zincblende structure.

The $\mathrm{Cd}_{1-x} \mathrm{Zn}_{x}$ Te alloys were made at the Massachusetts Institute of Technology, by 
reacting the $99.9999 \%$ pure elemental constituents in evacuated and sealed quartz tubes. The sample $\mathrm{x}$ values of $0,0.2,0.3,0.5$, 0.9 and 1 were calculated from the mass densities. These precast alloys were regrown by directional solidification in a Bridgman-Stock-barger-type crystal-growth furnace. Regrowth occurred at the rate of $1.2 \mathrm{~mm} / \mathrm{h}$ in the furnace adiabatic zone with a temperature gradient of about $15^{\circ} \mathrm{C} / \mathrm{cm}$. the resulting boules were annealed at $600^{\circ} \mathrm{C}$ in a Cd-saturated atmosphere for about $5 \mathrm{~d}$. Their surfaces were prepared by lapping, mechanical polish, and etching in bromine-methanil solution.

Fourier transform infrared (FTIR) reflectivity measurements were made using facilities at National Taiwan Normal University described elsewhere [14]. A DTGS detector, for good signal-to-noise ratios-between 40 and $240 \mathrm{~cm}^{-1}$ with resolution of $0.1 \mathrm{~cm}^{-1}$ were employed to the Bruker IFS66 infrared spectrometer. Data were taken at near-normal incidence and at temperature of $300 \mathrm{~K}$. The incident angle was about $9^{\circ}$ degrees, a negligible deviation from normal incidence. The reflection coefficient was measured by ratioing the intensity of the light reflected form the sample against that reflected form a reference mirror made of coin silver with about $99 \%$ reflectance.

\section{Results and discussion}

\section{A. Experiment result}

In Figure 1 and Figure 2 display the FTIR reflectivity spectra of the $\operatorname{six} \mathrm{CdZn}_{\mathrm{x}} \mathrm{Te}_{1-\mathrm{x}}$ sample at 300 and the four $\mathrm{CdSe}_{\mathrm{x}} \mathrm{Te}_{1-\mathrm{x}}$ samples, respectively. Below $170 \mathrm{~cm}^{-1}$, the regular reststrahlen band characteristic of the CdTe-like TO phonon is seen in all the samples at $300 \mathrm{~K}$. Beyond $170 \mathrm{~cm}^{-1}$, there is a CdSe-like TO band which grows with $\mathrm{x}$ and splits into two bands. From Table 2 we can see that there is a mix mode between CdTe-like TO mode and ZnTe-like TO mode. This indicates that the third peak comes from the bulk, not from the surface, because infrared excitation penetrates into the sample deeply. A bulk origin for the third peak strengthens the earlier interpretation that it comes from non-random cluster effects.

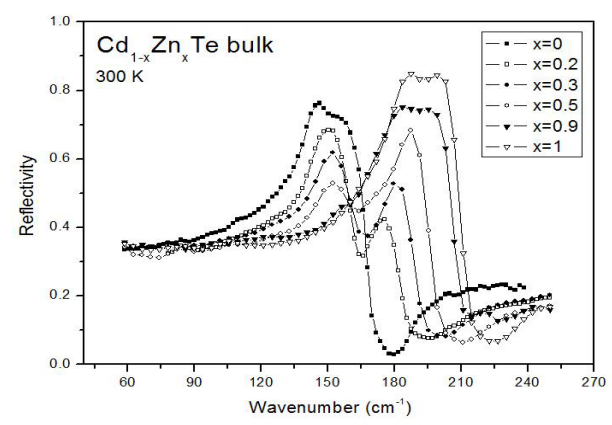

Figure 1. FTIR reflectivity of bulk $\mathrm{Cd}_{1-\mathrm{x}} \mathrm{Zn}_{\mathrm{x}} \mathrm{Te}$ at $300 \mathrm{~K}$, with $\mathrm{x}=0,0.2,0.3,0.5,0.9$ and 1. 


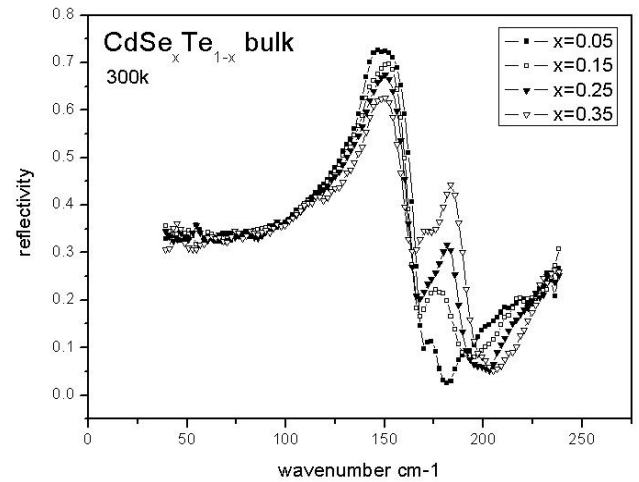

Figure 2. FTIR reflectivity of bulk $\mathrm{CdSe}_{\mathrm{x}} \mathrm{Te}_{1-\mathrm{x}}$ at 300 $\mathrm{K}$, with $\mathrm{x}=0.05,0.15,0.25$, and 0.35 .

In Figure 3 and Figure 4 shows the FTIR reflection spectra of $\mathrm{Cd}_{1-\mathrm{x}} \mathrm{Zn}_{\mathrm{x}}$ Te with $x$ from o to 1 , measured at $300 \mathrm{~K}$, and $\mathrm{CdSe}_{\mathrm{x}} \mathrm{Te}_{1-\mathrm{x}}$ with $x$ from 0.05 to 0.35 , measured at $300 \mathrm{~K}$. For mixed crystal, there are two $x$-dependent transverse modes, denoted $\mathrm{TO} 1$ and $\mathrm{TO} 2$, with oscillator strengths $S 1$ and $S 2$, as shown in Table 1 and Table 2 respectively. Figure 3 shows the FTIR reflection spectra of $\mathrm{Cd}_{1-\mathrm{x}} \mathrm{Zn}_{\mathrm{x}}$ Te with $x$ from o to 1 , measured at $300 \mathrm{~K}$. The vibration mode occurring in $139.8 \mathrm{~cm}^{-1}$ for $x=0$ at $300 \mathrm{~K}$ is referred to as the CdTe-like mode (TO1). Also assign the ZnTe-like mode (TO2) to $180.194 \mathrm{~cm}^{-1}$ for $x=1$ at $300 \mathrm{~K}$. We observed that the CdTe-like TO mode is around 139-153 $\mathrm{cm}^{-1}$ for different $\mathrm{Zn}$ composition at $300 \mathrm{~K}$, and the ZnTe-like TO vibration mode is around $170-181 \mathrm{~cm}^{-1}$. The vibration mode occurring in $141.3 \mathrm{~cm}^{-1}$ in Figure 4 for $x=0.05$ at $300 \mathrm{~K}$ is referred to as the CdTe-like mode (TO1). We can also assign the CdSe-like mode (TO2) to $174.0 \mathrm{~cm}^{-1}$ for $x$ $=0.05$ at $300 \mathrm{~K}$. We observed that the CdTe-like TO mode is around 141-146 $\mathrm{cm}^{-1}$ for different Se composition at $300 \mathrm{~K}$, and the CdSe-like TO vibration mode is around $173-181 \mathrm{~cm}^{-1}$.

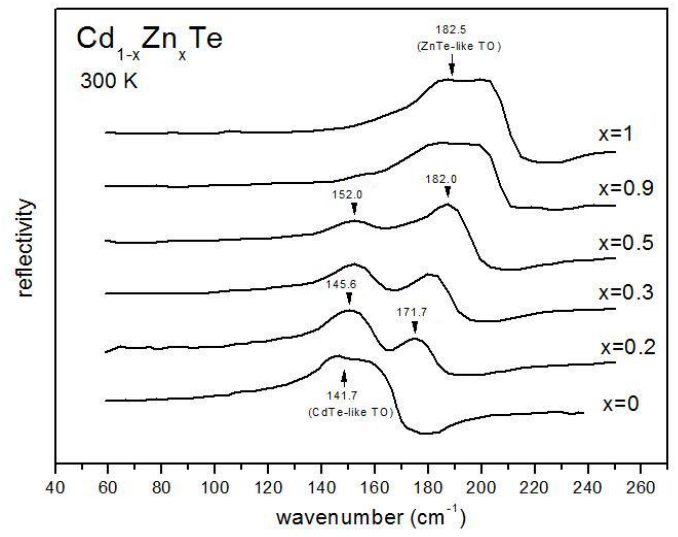

Figure 3. The FIR reflectance spectra of

$\mathrm{Cd}_{1-\mathrm{x}} \mathrm{Zn}_{\mathrm{x}} \mathrm{Te}$ for $\mathrm{Zn}$ composition $x=0$ to 1 at $300 \mathrm{~K}$.

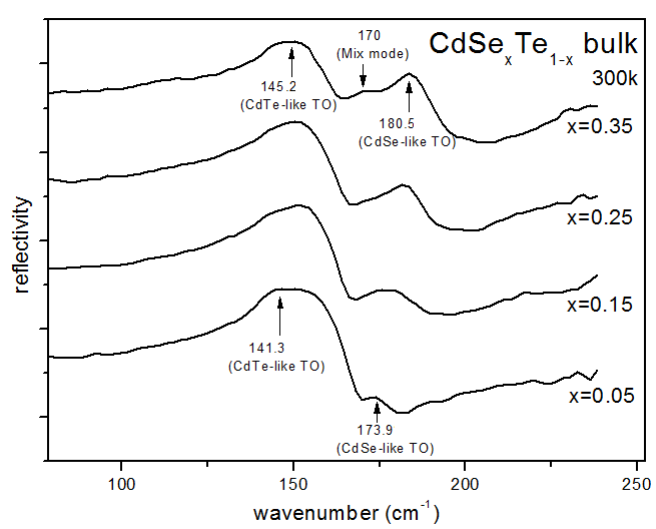

Figure 4. The FIR reflectance spectra of $\mathrm{CdSe}_{\mathrm{x}} \mathrm{Te}_{1-\mathrm{x}}$ for Se composition $x=0.05$ to 0.35 at $300 \mathrm{~K}$.

\section{B. Theoretical fits of FIR reflectance}

From a classical model, the FIR dielectric response function can be expressed as 


$$
\varepsilon(\omega)=\varepsilon_{\infty}+\frac{S_{j} \omega_{T_{j}}^{2}}{\left(\omega_{T_{j}}^{2}-\omega^{2}-i \gamma_{j} \omega\right)}-\frac{\omega_{p}^{2}}{\omega\left(\frac{\omega+i}{\tau}\right)}
$$

where $\varepsilon_{\infty}$ is the high frequency dielectric constant, $\omega_{T j}, S_{j}$ and $\tau_{j}$ are the frequency, strength, and damping constant of the jth TO mode, respectively. The last term in the equation represents the free carrier contribution with a carrier scattering time $\tau$ and a plasma frequency

$$
\omega_{p}=\left(\frac{4 \pi n e^{2}}{m *}\right)^{\frac{1}{2}} \text {. }
$$

where $n$ is the carrier concentration and $m^{*}$ is the effective mass. Computer Least-Square fittings were performed for all the FIR spectra in Figure 1 and Figure 2. The vibration modes and other parameters of the optical modes at Figure 1 and Figure 2 of $300 \mathrm{~K}$ obtained from these theoretical fits are collected in Table 1 and Table 2. The CdTe-like TO, CdSe-like TO vibration modes versus $\mathrm{x}$ values are shown in Figure 5 and Figure 6 . The values of mode frequency, strength, and phonon relaxation factor or damping constant of each band depend on the detailed composition of samples. The $\mathrm{Zn}$ concentration dependence of the strength of CdTe-like and ZnTe-like TO phonon modes is illustrated in Figure 7 and the Se concentration dependence of the strength of CdTe-like and CdSe-like TO phonon modes is illustrated in Figure 8. This shows that the strength of CdTe-like mode is decreasing and the strength of CdSe-like mode is increasing with increasing Se composition.

From the dielectric function $\varepsilon$ for a system with two oscillators, the strength of TO1 and TO2 can be expressed as

$$
\begin{aligned}
& S_{1} \omega_{T 1}^{2}=\varepsilon_{\infty} \frac{\left(\omega_{L 1}^{2}-\omega_{T 1}^{2}\right)\left(\omega_{L 2}^{2}-\omega_{T 1}^{2}\right)}{\omega_{T 2}^{2}-\omega_{T 1}^{2}} \\
& S_{2} \omega_{T 2}^{2}=\varepsilon_{\infty} \frac{\left(\omega_{L 1}^{2}-\omega_{T 2}^{2}\right)\left(\omega_{L 2}^{2}-\omega_{T 2}^{2}\right)}{\omega_{T 1}^{2}-\omega_{T 2}^{2}}
\end{aligned}
$$

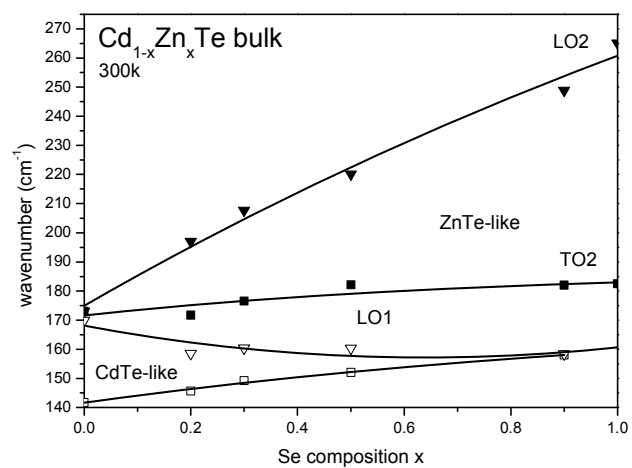

Figure 5. Optical mode frequency versus $x$ from epitaxial $\mathrm{Cd}_{1-x} \mathrm{Zn}_{x}$ Te bulk at $300 \mathrm{~K}$. The solid line are the fitting results, and the dash line is the predicted of LO1 and LO2.

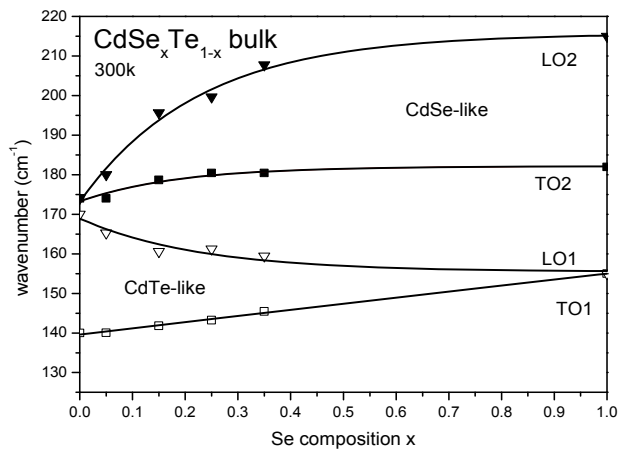

Figure 6. Optical mode frequency versus $\mathrm{x}$ from epitaxial $\mathrm{CdSe}_{\mathrm{x}} \mathrm{Te}_{1-\mathrm{x}}$ bulk at $300 \mathrm{~K}$. The solid line are the fitting results, and the dash line is the predicted of LO1 and LO2. 


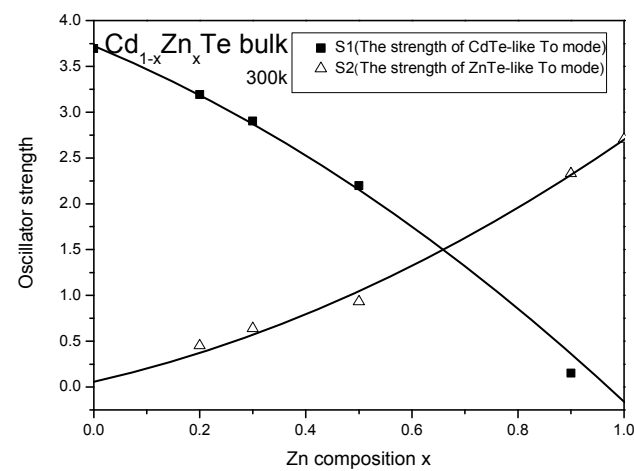

Figure 7. The mode strength of TO1 and TO2 versus $\mathrm{Zn}$ composition $\mathrm{x}$ at $300 \mathrm{~K}$.

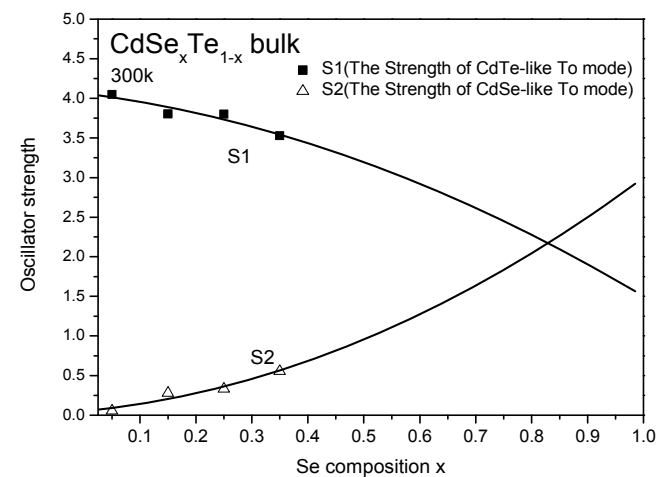

Figure 8. The mode strength of TO1 and TO2 versus Se composition $\mathrm{x}$ at $300 \mathrm{~K}$.

\section{Electrical conductivity}

The electrical properties of these bulk $\mathrm{Cd}_{1-\mathrm{x}} \mathrm{Zn}_{\mathrm{x}} \mathrm{Te}$ and $\mathrm{CdSe}_{\mathrm{x}} \mathrm{Te}_{1-\mathrm{x}}$ wafers can also be characterized by fitting the dielectric function. The obtained parameter data for the high-frequency limit dielectric constant, free carrier concentration, mobility, conductivity and effective mass are listed in Table 3 and Table 4.

Table 1. Optical constant of $\mathrm{Cd}_{1-\mathrm{x}} \mathrm{Zn}_{\mathrm{x}} \mathrm{Te}$ by dielectric function fitting at $300 \mathrm{~K}$.

\begin{tabular}{cccccccc}
\hline \hline $\mathrm{Cd}_{1-\mathrm{x}} \mathrm{Zn}_{\mathrm{x}} \mathrm{Te}$ & $300 \mathrm{~K}$ & \multicolumn{3}{c}{ CdTe-like mode } & \multicolumn{3}{c}{ CdSe-like mode } \\
$\mathrm{x}$ & $\varepsilon_{\infty}$ & $\mathrm{S}_{1}$ & $\omega_{\mathrm{TO} 1}\left(\mathrm{~cm}^{-1}\right)$ & $\gamma\left(\mathrm{cm}^{-1}\right)$ & $\mathrm{S}_{2}$ & $\omega_{\mathrm{TO} 2}(\mathrm{~cm}-1)$ & $\gamma\left(\mathrm{cm}^{-1}\right)$ \\
\hline 0 & 8.51546 & 3.69633 & 141.742 & 6.83041 & & & \\
0.2 & 8.16634 & 3.19091 & 145.638 & 9.28233 & 0.45347 & 171.727 & 10.858 \\
0.3 & 7.96 & 2.90354 & 149.188 & 12.9 & 0.63887 & 176.518 & 7.2982 \\
0.5 & 7.80613 & 2.19916 & 152.031 & 13.7206 & 0.93155 & 182.067 & 5.59974 \\
0.9 & 7.048 & 0.15 & 158 & 15 & 2.33075 & 182 & 3.98879 \\
1 & 6.91 & & & & 3.13523 & 182.5 & 3.32447 \\
\hline \hline
\end{tabular}


Table 2. Optical constant of $\mathrm{CdSe}_{\mathrm{x}} \mathrm{Te}_{1-\mathrm{x}}$ by dielectric function fitting at $300 \mathrm{~K}$.

\begin{tabular}{ccccccccccc}
\hline \hline $\mathrm{CdSe}_{\mathrm{x}} \mathrm{Te}_{1-\mathrm{x}}$ & $300 \mathrm{~K}$ & \multicolumn{2}{c}{ CdTe-like } & mode & \multicolumn{2}{c}{ CdSe-like } & mode & \multicolumn{2}{c}{ mix mode } \\
$\mathrm{x}$ & $\varepsilon_{\infty}$ & $\mathrm{S}_{1}$ & $\omega_{\mathrm{TO} 1}\left(\mathrm{~cm}^{-1}\right)$ & $\gamma\left(\mathrm{cm}^{-1}\right)$ & $\mathrm{S}_{2}$ & $\omega_{\mathrm{TO} 2}\left(\mathrm{~cm}^{-1}\right)$ & $\gamma\left(\mathrm{cm}^{-1}\right)$ & $\mathrm{S}_{2}$ & $\omega_{\mathrm{TO} 2}\left(\mathrm{~cm}^{-1}\right)$ & $\gamma\left(\mathrm{cm}^{-1}\right)$ \\
\hline 0.05 & 8.58989 & 4.04911 & 140.064 & 8.62977 & 0.05362 & 173.994 & 7.53641 & & & \\
0.15 & 8.73688 & 3.80198 & 141.809 & 8.0333 & 0.28025 & 178.666 & 17.1627 & 0.05689 & 174.476 & 10.1078 \\
0.25 & 8.86326 & 3.93729 & 142.249 & 10.4346 & 0.3339 & 180.416 & 11.3184 & 0.09586 & 172 & 10.1078 \\
0.35 & 9.07434 & 3.52746 & 145.459 & 12.8877 & 0.55399 & 180.423 & 11.8251 & 0.25081 & 170 & 9.7605 \\
\hline \hline
\end{tabular}

Table 3. Electric properties of $\mathrm{Cd}_{1-\mathrm{x}} \mathrm{Zn}_{\mathrm{x}} \mathrm{Te}$ characterized by dielectric function fitting at $300 \mathrm{~K}$.

\begin{tabular}{|c|c|c|c|c|}
\hline $\begin{array}{c}\mathrm{Cd}_{1-\mathrm{x}} \mathrm{Zn}_{\mathrm{x}} \mathrm{Te} 300 \mathrm{~K} \text { Carrier } \\
\mathrm{x}\end{array}$ & $\begin{array}{l}\text { Concentration } \\
\left(10^{18}\right)\end{array}$ & $\begin{array}{l}\text { Mobility } \\
\text { (cm2/V.s) }\end{array}$ & $\mathrm{m}^{*} / \mathrm{m}_{\mathrm{e}}$ & $\begin{array}{l}\text { Conductivity } \\
\left(\text { ohm- } \mathrm{cm}^{-2}\right)\end{array}$ \\
\hline 0 & 2.05741 & 1.92721 & 0.11 & $6.34 \mathrm{E}-19$ \\
\hline 0.2 & 4.82526 & 1.89733 & 0.11032 & $1.46 \mathrm{E}-18$ \\
\hline 0.3 & 4.3513 & 2.09582 & 0.11192 & $1.46 \mathrm{E}-18$ \\
\hline 0.5 & 5.4275 & 2.78045 & 0.11798 & $2.41 \mathrm{E}-18$ \\
\hline 0.9 & 5.49579 & 6.35942 & 0.14168 & $5.59 \mathrm{E}-18$ \\
\hline 1 & 5.39771 & 7.15874 & 0.15 & $6.18 \mathrm{E}-18$ \\
\hline
\end{tabular}

Table 4. Electric properties of $\mathrm{CdSe}_{\mathrm{x}} \mathrm{Te}_{1-\mathrm{x}}$ characterized by dielectric function fitting at $300 \mathrm{~K}$.

\begin{tabular}{|c|c|c|c|c|c|}
\hline $\begin{array}{c}\mathrm{CdSe}_{\mathrm{x}} \mathrm{Te}_{1-\mathrm{x}} 300 \mathrm{~K} \\
\mathrm{x}\end{array}$ & Carrier & $\begin{array}{l}\text { Concentration } \\
\left(10^{18}\right)\end{array}$ & $\begin{array}{l}\text { Mobility } \\
\text { (cm2/V.s) }\end{array}$ & $\mathrm{m}^{*} / \mathrm{m}_{\mathrm{e}}$ & $\begin{array}{l}\text { Conductivity } \\
\left(\mathrm{ohm}-\mathrm{cm}^{-2}\right)\end{array}$ \\
\hline 0.05 & & 0.0057 & 0.91639 & 0.19655 & $2.49 \mathrm{E}-22$ \\
\hline 0.15 & & 0.00573 & 0.36328 & 0.18995 & $1.59 \mathrm{E}-22$ \\
\hline 0.25 & & 0.00567 & 0.29831 & 0.18375 & $2.71 \mathrm{E}-22$ \\
\hline 0.35 & & 0.00589 & 0.23131 & 0.17795 & $2.18 \mathrm{E}-22$ \\
\hline
\end{tabular}




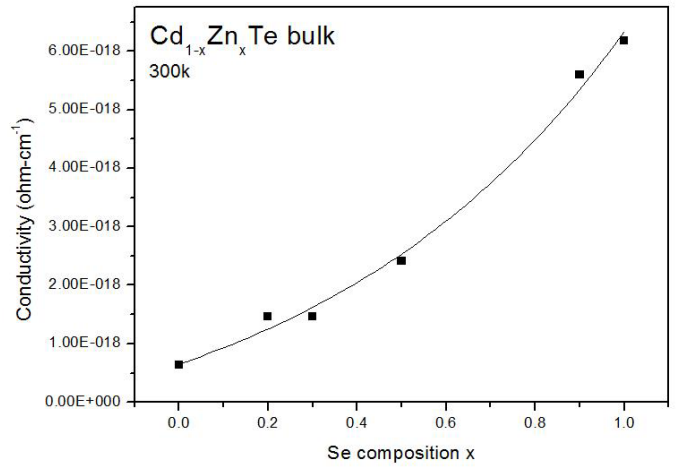

Figure 9. The dependence of the conductivity of the $\mathrm{Cd}_{1-\mathrm{x}} \mathrm{Zn}_{\mathrm{x}} \mathrm{Te}$ epilayer with the $\mathrm{Zn}$ composition $\mathrm{x}$ at $300 \mathrm{~K}$.

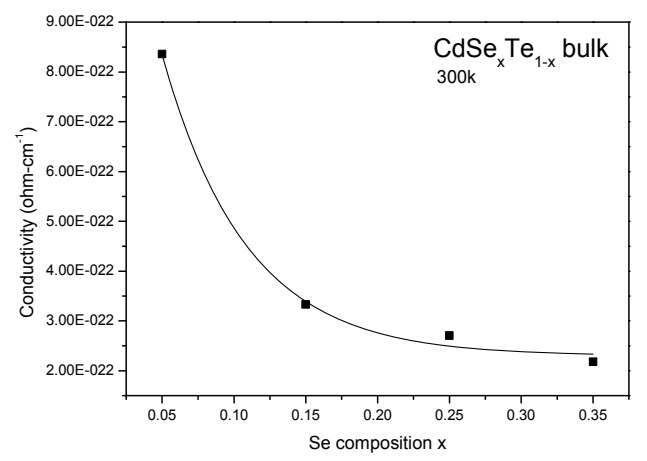

Figure 10. The dependence of the conductivity of the $\mathrm{CdSe}_{\mathrm{x}} \mathrm{Te}_{1-\mathrm{x}}$ epilayer with the Se composition $\mathrm{x}$ at $300 \mathrm{~K}$.

\section{Conclusion}

A multi-technique study using FTIR reflectance has been made on Bridgman-grown bulk $\mathrm{CdSe}_{\mathrm{x}} \mathrm{Te}_{1-\mathrm{x}}$ with zincblende structure $(\mathrm{x}<0.36)$. We have grown a series of $\mathrm{Cd}_{1-\mathrm{x}} \mathrm{Zn}_{\mathrm{x}} \mathrm{Te}$ and $\mathrm{CdSe}_{\mathrm{x}} \mathrm{Te}_{1-\mathrm{x}}$ epilayers, with a large range of $\mathrm{Zn}$ composition from $0 \%$ to $100 \%$, and $\mathrm{Se}$ composition from $15 \%$ to $35 \%$. From Figure 9 and Figure 10 we can see that the phonon modes vary by $\mathrm{x}$ are regulative, so the far infrared reflection spectra shows the good optical quality of these samples. Theoretical fits through a classical model with the FIR dielectric response function were performed on FIR reflectivity spectra of all the samples. Composition dependent optical parameters of transverse phonon mode frequency, strength, damping constant have been deduced. With an increase of $\mathrm{Zn}$ composition $\mathrm{x}$, the CdTe-like TO phonon mode frequency and damping factor increase, but oscillator strength decreases, while the ZnTe-like TO phonon mode frequency and strength increase, and damping factor decreases with increasing $\mathrm{x}$. And with increase of Se composition $\mathrm{x}$, the CdTe-like TO phonon mode frequency and damping factor increase, but oscillator strength decreases, while the CdSe-like TO phonon mode frequency and strength increase, and damping factor decreases with increasing $\mathrm{x}$. Detailed analyses of FIR reflectance and dielectric function have also led to the knowledge of electrical properties of $\mathrm{Cd}_{1-\mathrm{x}} \mathrm{Zn}_{\mathrm{x}} \mathrm{Te}$, including the high-frequency limit dielectric constant, free carrier concentration, mobility, conductivity and effective mass. With increasing $\mathrm{x}$, and $\mathrm{m} *$ increase slightly, mobility and conductivity increase greatly. Further analyses of FIR reflectance and 
dielectric function have also led to the knowledge of electrical properties of $\mathrm{CdSe}_{\mathrm{x}} \mathrm{Te}_{1-\mathrm{x}}$. With increasing $\mathrm{x}$, and $\mathrm{m} *$ increase slightly, mobility and conductivity decrease greatly. These predict a strong effect of $\mathrm{Zn}$ and Se composition dependence on the electrical properties of mobility and conductivity, which is useful for device application of this material.

\section{References}

[1] S.M. Babu, T. Rajalakshmi, R. Dhanasekaran and P. Bamasamy, J. Crystal Growth 110 (1991) 423.

[2] M. Bouroushian, Z. Loizos, N. Spyrellis and G. Maurin, Thin Solid Films 229 (1993) 101.

[3] M.S. Brodin, N.I. Vitrikhovskii, A.A. Kipen and I.B. Mizetskaya, Sov. Phys.-Semicond. 6 (1972) 601.

[4] L.V. Prytkina, V.V. Volkov, A.N. Mentser, A.V. Vanyukov and P.S. Kireev, Sov. Phys.-Semicond. 2 (1968)509.

[5] H. Tai, S. Nakashima and S. Hori, Phys. Status Solidi (a) 30 (1975) K115.

[6] M.J. Nahory, S.P. Brasel and M. Tamargo, in: Semiconductor Interfaces and Microstructures, Ed. Z.C. Feng (World Scientific, Singapore, 1992) p. 238.

[7] M. Gorska and W. Nazarewicz, Phys. Status Solidi (b) 57 (1973) K65; 65 (1974) 193.
[8] E.A. Vinogradov, L.K. Vodop'yanov and G.S. Oleinik, Sov. Phys.-Solid State 15 (1973) 322

[9] V.G. Plotnichenko, L.V. Golubev and L.K. Vodop'yanov, Sov. Phys.-Solid State 19 (1977) 1582.

[10] S. Perkowitz, L.S. Kim and P. Becla, Phys. Rev. B 43 (1991) 6598.

[11] H. Narada and S.Narita, J. Phys. Soc. Jpn. $30,1628(1970)$.

[12] L. K. Vodop'yanov, E. A. Vinogradov, A. M. Blinov, and V. A. Rukavishnikov, Fiz. Tverd. Tela (leningrand) 14, 268 (1972) [Sov. Phys.-Solid State 14,219 (1972)]

[13] E. A. Vinogradov and L. K. Vodop'yanov, Fiz. Tverd. Tela (Leninrgrad) 17,3161 (1975) [Sov. Phys.-Solid State17, 2088 (1976)].

[14] M. Macler, Z.C. Feng, S. Perkowitz, R. Rousina and J. Webb, Phys. Rev. B 46(1992) 6902. 